\title{
On the Design of Complex Energy Systems: Accounting for Renewables Variability in Systems Sizing
}

\author{
Oluwamayowa O. Amusat ${ }^{\mathrm{a}}$, Paul R. Shearing ${ }^{\mathrm{b}}$, Eric S. Fraga, ${ }^{\mathrm{a}, *}$ \\ ${ }^{a}$ Centre for Process Systems Engineering, Department of Chemical Engineering, University College London, Torrington \\ Place, London WC1E 7JE, United Kingdom \\ ${ }^{b}$ Electrochemical Innovation Lab, Department of Chemical Engineering, University College London, Torrington Place, \\ London WC1E 7JE, United Kingdom
}

\begin{abstract}
The variability challenge inherent in the design and sizing of stand-alone renewables-based energy systems incorporating storage is addressed at the design stage. The framework developed for reliability evaluation combines the stochastic modelling of renewable resources with chronological simulation of energy system performance for the evaluation of system reliability. The effect of inter-year variability is quantified by using a modified form of the loss of power supply probability as the reliability objective. A bi-criteria problem of capital cost minimization and reliability maximization is solved for two cases of remotely-located mining operations in Chile and Canada to demonstrate the capabilities of the methodology. Approximations to the Pareto-optimal fronts generated using a multi-objective genetic algorithm (NSGA-II). The performances of the minimum-cost designs generated are investigated in each case. The methodology provides the decision maker with necessary information about a number of alternative designs based on which sizing decisions may be made.
\end{abstract}

Keywords: Energy storage, multi-objective optimization, reliability, renewables variability, systems design

\footnotetext{
*Corresponding author

Email addresses: oluwamayowa.amusat.13@ucl.ac.uk (Oluwamayowa O. Amusat), p.shearing@ucl.ac.uk (Paul R. Shearing), e.fraga@ucl.ac.uk (Eric S. Fraga)
} 
the identification of appropriate combinations of both generating and storage technologies which minimize the cost of energy system while satisfying certain reliability requirements.

Several works in literature incorporate the reliability concept in the design of stand-alone hybrid energy systems (Yang et al., 2008, Tina and Gagliano, 2008; Diaf et al., 2008, Yang et al., 2009, Al-Shamma'a and Addoweesh, 2014, Kaabeche and Ibtiouen, 2014). Some of the works consider reliability as a constraint in systems design and sizing (Tina and Gagliano, 2008, Yang et al., 2009, Al-Shamma'a and Addoweesh, 2014), while others treat reliability as one of the objectives in multi-criteria problems, generating Paretooptimal solution sets. Chauhan and Saini (2014) present a review of literature on the design of stand-alone renewables-based power systems. Of particular interest are the works which consider cost-reliability multiobjective design with reliability as one of the objectives.

The multi-objective design of a hybrid PV-wind-battery system for cost and reliability was considered by Yang et al. (2008). The cost was modelled as an annualized cost of system (ACS), while the reliability was represented as a loss of power probability (LPSP). Diaf et al. (2008) considered the sizing of a similar standalone hybrid system for Corsica Island, with the cost model based on the levelized cost of electricity (LCOE). The work by Ould Bilal et al. (2010) considered the effect of the load demand profile on the design of hybrid PV-wind-battery systems. The ACS and LPSP were considered as objectives, with the bi-criteria problem solved using a genetic algorithm. The triple multi-objective design of an isolated hybrid system integrating PV-wind-diesel generation with hydrogen and battery storage was investigated by Dufo-Lopez and Bernal-Agustin (2008). The work considered the minimization of the net present cost (NPC) of the energy system, $\mathrm{CO}_{2}$ emissions and the unmet load (kWh/year), and presented $2 \mathrm{D}$ and $3 \mathrm{D}$ representations of the Pareto fronts. Abbes et al. (2014) also considered the triple multi-objective design of a PV-wind-battery system for cost, reliability and environmental impact using a genetic algorithm. The cost was represented by a life cycle cost (LCC), while the LPSP was considered as the reliability measure.

A survey of the literature reveals that most of the work done so far involving storage has been geared towards the design of electricity-based renewables generation systems (PV/wind) and are based on fixed renewable input conditions. The reliability objectives implemented in these works represent the performance of the energy system within a fixed time period (typically one year, $8760 \mathrm{~h}$ ). In reality, renewables are variable: no two years have exactly the same amount of wind or solar radiation. While probabilistic approaches to reliability evaluation have been developed by some researchers to account for renewables variability in the sizing of PV-wind systems (Tina et al. 2006, Khatod et al. 2010), the approaches do not extend to the sizing of systems involving storage (Chauhan and Saini 2014). We have previously shown (Amusat et al. 2016) that variability can have a significant effect on the cost and performance of energy systems incorporating storage and therefore must be accounted for at the design stage.

Here, we address the variability challenge inherent in the sizing of complex renewables-based energy systems by developing a methodology which accounts for inter-year variability at the design stage in the form of a reliability objective in a bi-criteria design problem. It extends our previous work (Amusat et al., 2016) in which a two-step approach was adopted in evaluating the effect of variability: "optimal" designs were first generated under deterministic input conditions and then stochastically analysed under a number of potential renewable input scenarios to obtain a measure of performance. The cost and reliability objectives were thus treated sequentially rather than simultaneously. While this sequential approach enabled us to gain an understanding of the impact of inter-year variability on design sizing and performance, it has the potential to generate too few points and miss solutions of interest along the Pareto frontier for high variability systems. This, combined with the tractability challenges encountered in applying the methodology to fullyear problems (only consecutive winter days were considered in the original work), make the approach unsuitable for decison making. This work seeks to overcome these shortcomings by developing a framework which allows the full Pareto front to be identified based on a full year of simulation, thereby providing insight on system performance based on which sizing decisions can be made.

\section{Energy System Description}

Consider an integrated energy system for an remotely-located mining operation with two generation and three storage options, as shown in Figure 1. 


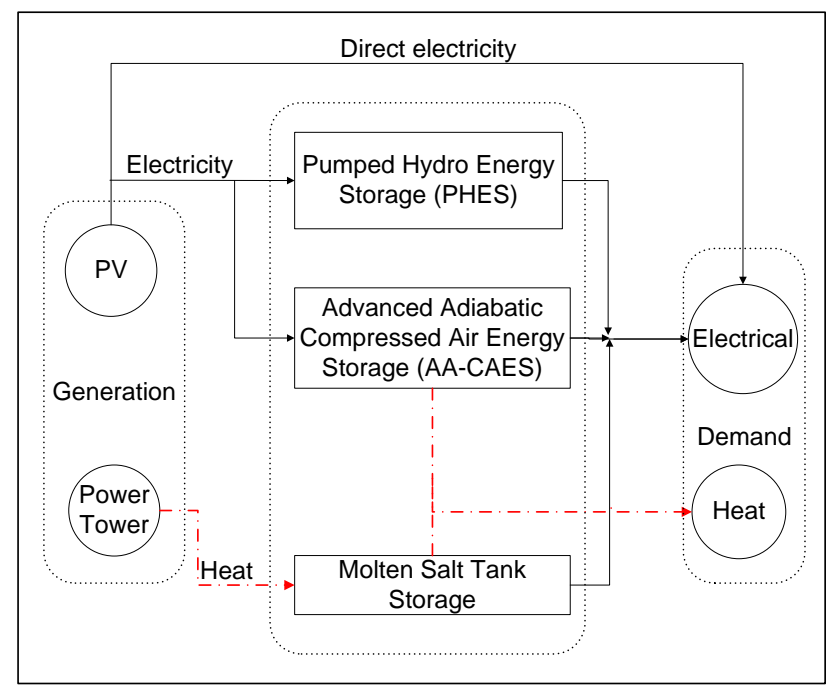

Figure 1: Proposed integrated energy system for mining operation. The solid black lines lines show the possible electricity network while the broken red lines represent heat.

The photovoltaic system consists of solar modules coupled with inverters. The solar modules convert energy from the sun into direct current, while the power-point tracking inverters convert from direct to alternating current. Concentrated solar power (also called power towers, PT) generate heat from the direct portion of solar radiation. The power tower consists of two major components: sun-tracking heliostats and an absorber. The heliostats reflect energy from the sun onto the absorber, where the energy is collected as heat. The thermal energy generated by the tower is transferred to molten salts, with the hot salt used for electricity generation through heating of steam for a turbine. Excess energy generated by either storage option is stored for use in times of insufficient generation.

Two technically mature options are available for the large scale storage of excess electricity and with largescale deliverability (greater than $10 \mathrm{MW}_{\mathrm{e}}$ ): pumped hydraulic energy storage (PHES) and advanced adiabatic compressed air energy storage (AA-CAES). Molten salt tank storage (MTS) is employed for the storage of any excess thermal generation. The methodology can be extended to include new storage technologies which may become available subsequently.

The plant must meet both thermal and electrical demands. The integrated energy system allows for the electrical demands of the process to be met directly from the PV system or from any of the storage options, while the thermal demands of the plant can be met from only the AA-CAES or molten salt systems.

For the system described above, the aim is to identify the trade-offs between cost and reliability for energy system designs which are required to meet thermal and electrical demands while taking into account possible inter-year variability in renewables availability at the location. The first stage of the problem is therefore to develop a reliability measure suitable for this purpose.

\section{Accounting for Inter-year Variability: Modified loss of power supply probability, $\overline{L P S P}_{m}$}

Power reliability analysis is an important step in any system design process involving renewables generation due to the variable nature of the resources. It provides information on generation-demand balancing (Chauhan and Saini, 2014). Several alternative measures for representing the reliability of energy systems exist, such as the energy index of reliability (EIR), the loss of power supply probability (LPSP) (Al-Shamma'a and Addoweesh, 2014; Yang et al., 2009), and the expected energy not supplied (EENS) (Tina et al. 2006, Chauhan and Saini | 2014). However, none of these measures can be used directly to account for variability between years. An enhanced reliability measure is required to include inter-year variability in the assessment of alternative designs.

The new measure is based on the conventional loss of power supply probability. The loss of power supply probability is defined as the probability that insufficient energy supply occurs when a hybrid energy system 
is unable to satisfy the load demand (Yang et al. 2003). It is a measure of the frequency of power system failure and has been used extensively (Al-Shamma'a and Addoweesh, 2014, Yang et al., 2009). The higher the value of the LPSP, the more likely it is for a design to fail.

Conventionally, (Al-Shamma'a and Addoweesh, 2014)

$$
L P S P=\frac{\sum_{t=0}^{T} P F T}{T}
$$

where $T$ is the number of hours of the study and PFT, power failure time [h], is the total time that the energy system is unable to satisfy demand. For the discrete system,

$$
L P S P=\frac{\sum_{\tau=0}^{n_{t}} P F T^{\prime}}{n_{t}}
$$

where $P F T^{\prime}$ refers to the number of discretized time intervals in which the energy system is unable to satisfy demand. Equation 2 gives the frequency of failure within a given time period. This definition takes into account only one time period of evaluation (usually one year $=8760 \mathrm{~h}$ ). In order to account for inter-year variability, the formula must be modified to account for multiple time periods.

We propose a new measure in which the reliability between years is measured in terms of the probability of satisfying a preset primary (within-year) reliability constraint. Consider $N$ years of renewable input data for a given location. Each of the $N$ years is considered as a potential input scenario for which the performance of the energy system is evaluated. A design is said to have failed in a given scenario if the reliability within the scenario is worse than an allowable threshold $R^{\prime}$. Based on this, the modified version of the loss of power supply probability, $\overline{L P S P}_{m}$, is:

$$
\overline{\operatorname{LPSP}}_{m}=\frac{\text { Number of scenarios in which design fails }\left(R_{i}<R^{\prime}\right)}{\text { Total number of scenarios }}=\frac{\left.N\right|_{R_{i}<R^{\prime}}}{N}
$$

where $R_{i}<R^{\prime}$ is the preset reliability condition (or internal constraint) which determines whether the performance in a given scenario is acceptable or not. Equation 3 incorporates two reliability measures: the primary reliability measure $R_{i}$, which forms part of the internal constraint and represents the expected level of performance within the year, and a secondary reliability measure $\overline{L P S P}_{m}$ which represents expected performance between years.

The modified LPSP measure is the frequency with which the set internal reliability constraint is violated by the design. The performance of the energy system in each input scenario is binary; it either fails or succeeds. As such, the output is probabilistic irrespective of the type of internal constraint implemented. The internal constraint sets the threshold performance for the designs to be generated as each design with $\overline{L P S P}_{m}<1$ will have satisfied the constraint at least once.

The design reliability is a function of the threshold $R^{\prime}$ : as the constraint is tightened by increasing $R^{\prime}$, the value assigned to the reliability of a given design will decrease. However, the modified LPSP does not account for the degree of failure: a design which fails by $1 \%$ in a scenario is no different from a design which fails by $20 \%$, for example. The internal (intra-year) reliability constraint may be based on any of the conventional reliability measures.

The measure provides information about design performance between (rather than within) scenarios. For example, a value of $\overline{L P S P}_{m}=0.1$ for the reliability measure

$$
\overline{\operatorname{LPSP}}_{m}=\frac{\left.N\right|_{E I R<80 \%}}{N}
$$

indicates that the design evaluated will only fail to meet at least $80 \%$ of the demands in $10 \%$ of input scenarios. Thus, both the internal and secondary reliability measures (which represent the system performance within and between scenarios) can be modified at the design stage, making the measure attractive. When considered as an objective in a bi-criteria problem, the resulting designs will have different probabilities of satisfying the constraint $R_{i}<R^{\prime}$.

The conventional loss of power supply probability (Equation 22 is considered as an internal constraint; it is the most frequently used measure of reliability within years (Chauhan and Saini, 2014). Given that the 
aim is to achieve full demand satisfaction for the mine from local generation, the designs generated must be capable of operation without external energy support $(L P S P=0)$. Thus, Equation 3 may be rewritten as

$$
\overline{\operatorname{LPSP}}_{m}=\frac{\left.N\right|_{L P S P>0}}{N}
$$

This is the measure that will be used in this work, which allows us to examine how frequently a given design will meet the required yearly performance given the potential variability in renewable energy generation at the location. To evaluate the measure however, two things are required: a way to generate multiple solar input scenarios which reflect the degree of variability at the location of the plant, and an energy system model to evaluate system performance for the whole year for any given input condition. These will be the focus of the next three sections.

\section{Solar radiation modelling and synthetic data generation}

The accuracy of the results obtained with the reliability measure described above will depend on the number of input scenarios considered. Large amounts of chronological data may be required to produce accurate and consistent results. In some cases, all the required data may be available in the form of historical measurements. However the historical data available are often insufficient or incomplete, and part (or all) of the input data must be obtained by some other means. For such cases, we need to be able to generate synthetic data with properties similar to what would be observed at the mine location. One way to do this is to base the synthetic data on the properties of the available historical data.

Photovoltaics require global horizontal irradiance (GHI) for power generation. Most meteorological stations collect instantaneous GHI data, typically hourly or half-hourly. For the location of interest, the available GHI data is collected and grouped into monthly data. For each month, the statistical properties of the data (mean, variance, skewness and kurtosis) at each time step are determined. Grouping into months allows us to have a sufficient number of data points to develop an adequate stochastic representation of variability at the location. It also minimizes the effect of errors and outliers as the dataset is larger.

\subsection{Generation of yearly GHI profiles}

An in-built MATLAB function pearsrnd, which determines the most appropriate distribution type and generates random data based on input statistical properties, was used in the generation of of yearly solar radiation data. The function is based on the Pearson family of distributions (Pearson, 1916) which consists of seven distribution types that cover the entire kurtosis-skewness region (Lahcene, 2013). While the mean and standard deviation provide information about the spread of the data, the skewness and kurtosis provide information about the shape of the required probability distribution.

Since the statistical properties of the historical data are evaluated on a monthly basis, a decision must be made on how the yearly data is generated. Two possible alternatives are:

1. Prediction of one solar profile for each month. With this technique, all days of the month are modelled to have exactly the same solar profile. The method assumes that all days of the month are similar to each other: the first day of January is similar to the thirty-first day, for example. For any given month with $d$ days, the instantaneous GHI may be represented mathematically as

$$
\dot{G}_{d, v}^{t o t}=f\left(g_{v}\right) \quad d=1 ; v=1,2 \ldots, n_{s}
$$

$$
\dot{G}_{d, v}^{\text {tot }}=\dot{G}_{1, v}^{\text {tot }} \quad d=2 \ldots, n_{\text {days }} ; v=1,2 \ldots, n_{s}
$$

where $v=1,2 \ldots, n_{s}$ are the discrete time periods for the statistical data, $g$ is the vector of statistical inputs for the month, and $n_{\text {days }}$ represents the number of days in the month.

2. Prediction of different daily solar profiles. With this method, a different solar profile is generated from the distribution for each day. This method assumes that the days of the month are completely independent of each other; availability on consecutive days of the month are not linked in any way (no trend). Mathematically,

$$
\dot{G}_{d, v}^{t o t}=f\left(g_{v}\right) \quad d=1 ; 2 \ldots, n_{\text {days }} ; v=1,2 \ldots, n_{s}
$$




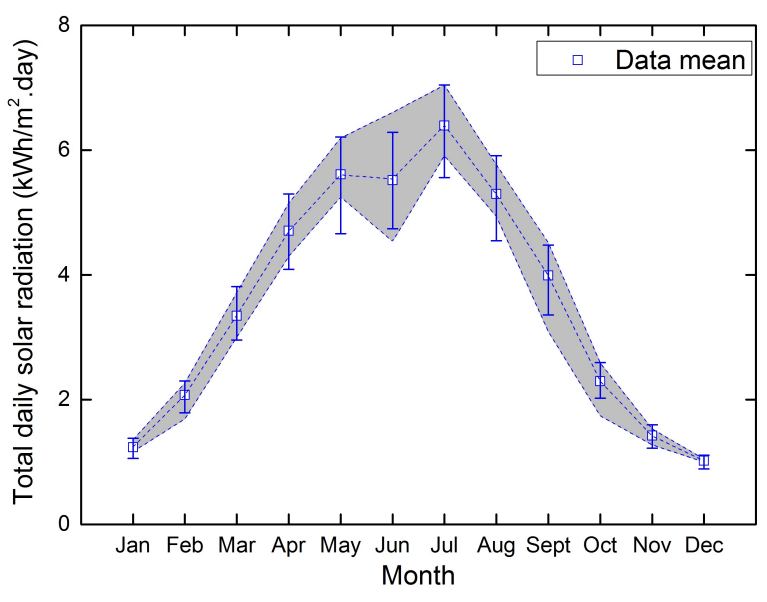

Figure 2: Comparison of monthly values obtained from simulation to historical data. The rectangles show the monthly means of the data obtained by simulation while broken line connects the monthly means of the historical data. The error bars show the range of values obtained from the model while the grey area represents the range of the historical data.

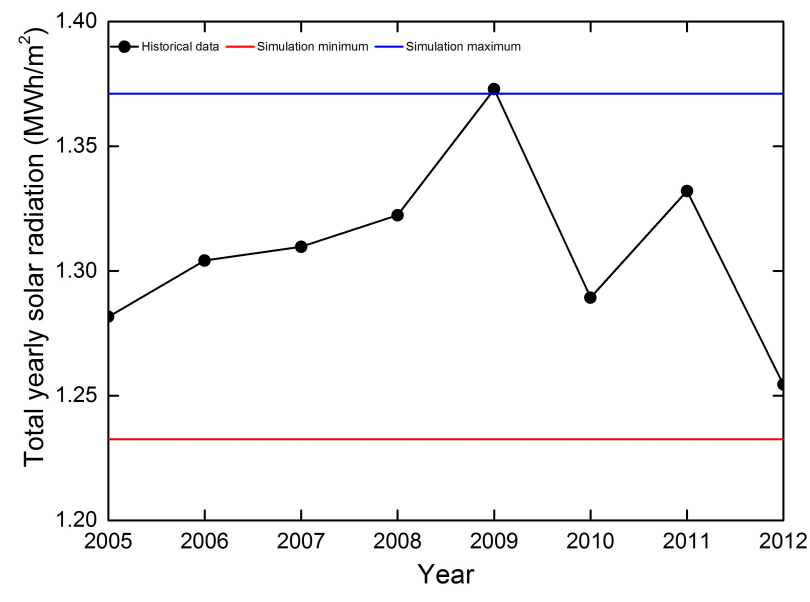

Figure 3: Comparison of simulated to historical total yearly solar radiation for Canada. The red and blue lines represent the minimum and maximum totals obtained for 500 simulated years. The black circles show the actual totals between 2005 and 2012. The range covered by the simulated data covers all but one year.

In reality, while no two days are ever exactly the same, weather data typically exhibits a trend-like component (consecutive cloudy days or an extremely sunny month, for example). As such, we consider a linear combination of data generated from the two approaches in this work:

$$
\begin{gathered}
\dot{G}_{1, v}^{t o t}=f\left(g_{v}\right) \quad v=1,2 \ldots, n_{s} \\
\dot{G}_{d, v}^{t o t}=\omega_{d} \cdot \dot{G}_{1, v}^{t o t}+\left(1-\omega_{d}\right) \cdot f\left(g_{v}\right) \quad \omega_{d} \epsilon[0,1] ; d=2 \ldots, n_{\text {days }} ; v=1,2 \ldots, n_{s}
\end{gathered}
$$

where $w_{d}$ is a weighting factor which determines how much trend is expected in the data. A value of $w_{d}=0$ indicates that no trend is expected. A value of $w_{d}=0.5$ was selected for the generation of the synthetic radiation profiles in this work, meaning that both the daily and monthly approaches contribute equally to the final profile. Thus, for each year to be simulated, two sets of data need to be generated (one with each method) and the corresponding values combined. One dataset provides individuality to all the days of the month. The other dataset provides a trend-like component, ensuring that days within the same month have some degree of similarity. This increases the chances of having events such as consecutive cloudy or sunny days. With this technique, we are able to retain the best properties of both schemes. However, no other steps were taken to explicitly account for extreme solar conditions in this work.

The approach assumes that the solar radiation available in consecutive hours are independent: $\dot{G}_{d, v}^{\text {tot }}$ is not influenced by $\dot{G}_{d, v-1}^{t o t}$. Other more complex approaches which account for trends in consecutive hours and/or days could also be developed. The methodology is general and allows for other types of trends and properties to be added to the solar profiles. Discretion was used in the choice of $w_{d}$ in this work. However, it can be chosen to reflect the type of climate typically observed at the site of interest. For example, high values of $w_{d}\left(0.5<w_{d}<1\right)$ could be selected for locations where the weather changes slowly and poor (or good) conditions typically last for a number of days or weeks. On the other hand, lower values of $w_{d}\left(0<w_{d}<0.5\right)$ would be required for locations where poor weather conditions simply pass through and clear up rapidly.

Figures 2 and 3 compare the properties of 500 sample simulated profiles to historical data for Canada, a location with high variability in solar resource. The results indicate that the predictions obtained from the yearly simulations agree well with the historical data available both on the monthly and yearly basis. The methodology also gives good results for other locations such as Chile, where the maximum and minimum values obtained for the yearly solar radiation were within $\pm 2 \%$ of those obtained from the historical data. 


\subsection{Generation of yearly DNI profiles}

Direct Normal Irradiance (DNI) data are required to calculate the instantaneous output of the power tower. However, the DNI available at any time is related to the GHI and cannot be modelled independently. As such, models linking both types of solar radiation must be used. The Louche model was used in calculating the beam irradiation from the GHI (Amusat et al. 2016). The beam radiation is related to the DNI through the solar zenith angle (Duffie and Beckman, 2013).

The GHI and DNI profiles generated by this methodology form the input into an energy system model (described in the next section) for the evaluation of system performance.

\section{Energy system model}

Consider the energy superstructure shown in Figure 1. Any design of the energy system will be defined by the sizes of the different generation and storage technologies within the superstructure. The sizes of the generation technologies $i$ are defined in terms of their nominal capacities $C_{i}^{g e n}$ [MW], whether electrical or thermal. For the storage technologies $j$, two components need to be considered: the amount of energy that the system can store, and the amount of power that the system can deliver. Electricity supply from storage requires the installation of mechanical equipment such as turbines for energy conversion, and these units have an impact on the cost of the energy system. The storage capacities $C_{j}^{s}$ [MWh] and rated electrical discharge capacities $C_{j}^{\text {out }}[\mathrm{MW}]$ of the technologies must therefore be sized separately in the optimization problem. From this, we see that any energy system design must be defined by three types of capacities,

$$
\bar{x}=\left\{C_{i}^{\text {gen }}, C_{j}^{s}, C_{j}^{\text {out }}\right\} \quad \forall i, j
$$

The components must be sized to meet both the peak electrical and thermal demands of the plant. The energy used to meet thermal load demand from storage is available in thermal form, so no additional equipment needs to be sized. No additional design variables are required for the thermal load. The cost of supplying heat only needs to be accounted for in the sizing of the generation and storage capacities. The peak electrical demands however require the sizing of generation, storage and discharge units.

Dynamic models describe the state evolution of the energy generation and storage sub-systems. The models rely on direct normal irradiance $\left(\dot{G}^{D N I}(t)\right)$ and global horizontal irradiance $\left(\dot{G}^{\text {tot }}(t)\right)$, which are generated as described in the previous section. Detailed information about the energy system models has been presented in previous works (Amusat et al. 2015, 2016).

\subsection{Model Implementation for yearly performance evaluation}

The differential-algebraic system of equations are discretised using Euler's forward differencing technique with a uniform time step $\Delta t$. The differential equation system is not stiff, so an Euler discretisation is sufficient. The result of the Euler discretization is a system of algebraic equations, for with $n_{t}$ intervals, $t \in\left[0, t_{\text {final }}\right]$, and $n_{t}=\frac{t_{\text {final }}}{\Delta t} . \tau=0, \ldots, n_{t}$ is the subscript used to represent the time dependent variables in the discrete time domain.

The discretized model for the hybrid energy system has been implemented in MATLAB 8.3 (MATLAB 2014).

The model was implemented in a step-wise manner. For each input scenario, evaluation of system model comprises of the repeating following steps at each time interval $\tau$ :

1. The outputs of the generation units $\dot{E}_{i, \tau}^{g e n}$ are calculated. The portion of the thermal and electrical loads that could be satisfied directly from the generation, as well as the excess generation, are determined. If shortfalls exist, go to step 2. If all demands have been satisfied, go to step 4 .

2. The thermal and electrical outputs of the storage units are determined. Due to the number of storage options and energy routes available in the superstructure, the problem of the order in which the options are operated (charged and discharged) within the system must be addressed.

Ideally, the order is determined at each time step to obtain the best overall performance of the system. In order to achieve this however, separate design variables for the charge and discharge phases would 


\section{Algorithm 1 Pseudocode for operating scheme implemented in energy system.}

Given: Design specifications $\bar{x}=\left\{C_{i}^{\text {gen }}, C_{j}^{s}, C_{j}^{\text {out }}, \overline{O P}\right\}$; demand requirements from storage $\left\{\dot{Q}_{\tau}^{\text {th }}, \dot{E}_{\tau}^{e l}\right\}$.

Output: Storage outputs $\left\{\dot{Q}_{j, \tau}^{\text {heating }}, \dot{E}_{j, \tau}^{\text {out }}\right\}$; Power shortfalls $\left\{\dot{S}_{\tau}^{\text {th }}, \dot{S}_{\tau}^{\text {el }}\right\}$

procedure DiSCHARGE SUB-MODEL

(a) Satisfy thermal demands

- Meet shortfall from MTS system $\dot{Q}_{1, \tau}^{\text {heating }}$.

- Evaluate heating requirement shortfall $\dot{S}_{\tau}^{\text {th }}$. If shortfall exists, try to meet from AA-CAES system $\dot{Q}_{2, \tau}^{\text {heating }}$.

- Re-evaluate heating requirement shortfall $\dot{S}_{\tau}^{\text {th }}=\dot{Q}_{\tau}^{\text {th }}-\dot{Q}_{1, \tau}^{\text {heating }}-\dot{Q}_{2, \tau}^{\text {heating }}$.

(b) Satisfy electrical demands

- Evaluate storage outputs $\dot{E}_{j, \tau}^{\text {out }}$ as specified by the operating scheme selected:

- If $\overline{O P}=1$, discharge storage in the order: AA-CAES - PHES - MTS.

- If $\overline{O P}=2$, discharge storage in the order: AA-CAES - MTS - PHES.

- If $\overline{O P}=3$, discharge storage in the order: MTS - AA-CAES - PHES.

- Evaluate electrical requirement shortfall $\dot{S}_{\tau}^{e l}=\dot{E}_{\tau}^{e l}-\sum_{j=1}^{3} \dot{E}_{j, \tau}^{\text {out }}$.

\section{end procedure}

Two factors were considered in determining the order in which the storage options are charged or discharged:

- the form in which the energy is stored, and

- the type of losses associated with the storage.

For heat supply, the MTS system takes precedence over the AA-CAES system.

For electricity storage, the discharge order of the PHES and AA-CAES systems is fixed based on the nature of the losses from the two systems. The PHES system only incurs losses (mechanical) when the system is being used. The AA-CAES system incurs losses whether the system is in use (mechanical losses) or not (thermal losses). Thus, when energy is available from both storage systems we have arbitrarily chosen to discharge the AA-CAES system first in order to minimize its thermal losses, irrespective of the mechanical efficiencies of the two systems. It should be noted that this does not influence the selection of technologies: the two storage types can still be selected individually or together. The constraint only dictates the order of operation when both technologies are available. However, this decision will have an impact on the solution space of the problem, as will be discussed later.

Three possible operating schemes for power supply from storage emerge once the order of discharge of the AA-CAES/PHES systems is constrained as described above. The alternative schemes are implemented in the model and an extra design variable $(\overline{O P})$ is used to select the scheme to use. Thus, the design vector is extended to contain an extra element to select the operating scheme:

$$
\bar{x}=\left\{C_{i}^{\text {gen }}, C_{j}^{s}, C_{j}^{\text {out }}, \overline{O P}\right\} \quad \forall i, j
$$


The implementation of the operating scheme reduces the complexity of the problem significantly as only one extra design variable needs to be optimized. However, it also introduces some limitations to the problem, as will be discussed later.

The electrical power output of any storage system over interval $\tau$ is dependent the unmet electrical load $\dot{S}_{\tau}^{e l}$, the current storage state $E_{j, \tau}^{s}$, and the dispatch capacity of the storage system $C_{j}^{o u t}$. The unmet load is re-evaluated after the dispatch each storage option to determine what is required from the next storage option. This procedure continues until either all of the storage options have been dispatched or all of the demand has been satisfied.

3. Evaluate total energy shortfall. Any shortfall (thermal or electrical) left after the dispatch of the all storage options will need to be supplied externally. External energy $E_{\tau}^{e x t}=\left[\dot{S}_{\tau}^{e l}+\dot{S}_{\tau}^{t h}\right] \cdot \Delta t$ is only required if energy from local generation and storage is insufficient to satisfy demand, thermal or electrical.

4. Evaluate storage end state. The PHES system is charged before the AA-CAES system due to the use-dependent nature of its losses. The storage level at the end of the time step $\tau$ forms the start state at the next time step $\tau+1$.

5 . When storage options become full, dump excess generation.

The steps are repeated for all $n_{t}$ intervals. This sequential approach mimics how plants are operated in reality: only the previous and current states of generation, storage level and demand are taken into account in decision making at each time step. Decision making requires no knowlege of future demand or renewable generation levels. At the end of the process, the LPSP of the system in the scenario is calculated with Equation 2. The model implemented here provides information about the performance within a given scenario and provides the required input information for the reliability between scenarios $\overline{L P S P}_{m}$.

\section{Implications of operating scheme}

The operating scheme specifies the order in which the technologies are operated. The introduction of the operating scheme does not exclude any possible technology and size combinations. However, it requires that some decisions are made a priori. As is usually the case, this has some implications on the problem and the solution space. Two potential impacts will be highlighted here.

The first impact has been mentioned previously: the order of discharge of the AA-CAES and PHES technologies has been fixed. This eliminates a portion of the solution space of the problem. The reduced solution space does not contain solutions in which the PHES system is discharged before the AA-CAES system.

The selection of an operating scheme also fixes the order of charging and discharging of the storage systems for the entire year. Together with the fact that generation is to be used to satisfy demands before storage is considered, some potential flexibility is removed from the system. For instance, the possibility of switching schemes within the year to improve performance is not available. This will have an impact on the results that will be obtained.

One specific impact of the fixed decisions is that peak shaving will not be possible. Consider one of the energy system configurations obtained in the previous work (Amusat et al., 2016) as shown in Figure 4.

The PT/MTS system was used as a base system for power supply while the PV/PHES systems were used at peak hours. This reduced the system cost because a smaller steam turbine was required for the MTS system. Off-peak periods refer to time intervals in which the MTS steam turbine capacity exceeded the electrical demand of the plant. During such periods, the demands of the plant were met by the PT/MTS system while all PV generation was used to charge the PHES system. On the other hand, peak periods are time periods in which the capacity from the MTS steam turbine was too small to meet the load demand. At such times, the deficit was covered by the PV during the day and by the PHES at night. This is an example of peak-shaving. Such a system was possible because the model allowed for the operating scheme to be changed at every time step. With the operating scheme introduced in this paper, the operating strategy of the generation and storage technologies is fixed for the entire year. This loss of freedom in decision-making prevents peak shaving from happening.

Despite the loss of flexibility described here, fixing some parts of the operating scheme allows us to be able to consider full years of operation which was not possible previously because of computational tractability 


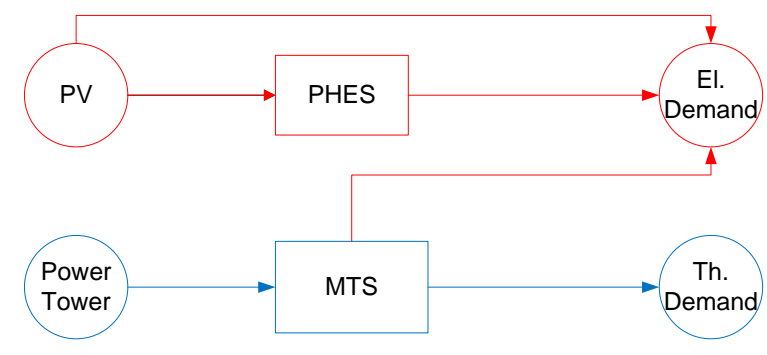

Figure 4: Sample energy system configuration with peak shaving (Source: Amusat et al. (2016)

challenges encountered with the full problem. This is a significant step forward because it means we are able to consider the impact of both inter-year and intra-year variability in renewable resources.

To summarize, in order to evaluate the reliability of a given design, a set of possible renewable input conditions is generated using the pearsrnd function and the Louche model (Section 4). The performance of the design within each input scenario is then evaluated with the energy system model (Sections 5 and 5.1), based on which the reliability between scenarios can be calculated as decribed in Section 3.

\section{Full Design Problem}

Having developed a suitable reliability measure to account for inter-year variability as well as a system model to evaluate performance under different input conditions, the system sizing problem can now be addressed. The problem can be stated as follows:

Given:

- historical information on the solar radiation for the location,

- the thermal and electrical energy requirements of the plant,

- the unit cost data for the generation and storage alternatives $\left(U_{i}^{\text {gen }}, U_{j}^{s}, U_{j}^{\text {out }}\right)$, and

- efficiencies of all mechanical units (pumps, turbines, compressors, motors, generators),

determine a non-dominated Pareto-optimal set of designs $\bar{X}=\left\{\bar{x}_{1}, \bar{x}_{2} \ldots \bar{x}_{n}\right\}$ which trade-off the minimisation of the capital cost $C C(\bar{x})$ of the energy system with the minimisation of the probability of failure $\overline{\operatorname{LPSP}}_{m}(\bar{x})$ :

$$
\min _{\bar{x} \in \bar{X}} z=\left(F_{1}, F_{2}\right)\left\{\begin{array}{l}
F_{1}(\bar{x})=C C(\bar{x}) \\
F_{2}(\bar{x})=\overline{L P S P}_{m}(\bar{x})
\end{array}\right.
$$

subject to generation, storage and operational constraints.

The capital cost of a design is the sum of the costs of the installed capacities of the generation and storage technologies,

$$
C C=\sum_{i=1}^{n_{g}} U_{i}^{\text {gen }} A_{i}^{\text {gen }}+\sum_{j=1}^{n_{s}}\left(U_{j}^{s} C_{j}^{s}+U_{j}^{\text {out }} C_{j}^{\text {out }}\right)
$$

where $n_{g}$ and $n_{s}$ are the number of generation and storage options, and $U_{i}^{g e n}, U_{j}^{s}$ and $U_{j}^{\text {out }}$ are the unit costs of the generation, storage and discharge units respectively.

The total electrical load at any time will be a sum of two components: the electrical power demand of the mine, and the electrical heating requirement for the molten salt storage tanks (Amusat et al., 2016). The second term is the electrical heating required to maintain the storage tanks at their required temperatures, counteracting the impact of thermal losses. It is proportional to the size of the MTS storage system. The thermal load consists of only the thermal demands of the plant. 
Table 1: NSGA-II parameters for case studies

\begin{tabular}{ll}
\hline Population size & $N_{\text {pop }}=100$ \\
Selection & Binary tournament selection \\
Crossover & Intermediate crossover, Crossover fraction $=0.1$ \\
Mutation & Gaussian mutation, mutation fraction $=0.1$ \\
Stopping criteria & Maximum number of generations, $N_{g}=300$ \\
\hline
\end{tabular}

\section{Solution strategy}

The bi-criteria problem to generate the non-dominated set of designs is solved using NSGA-II (Deb et al. 2002), a non-dominated sorting-based multiobjective evolutionary algorithm (MOEA) as implemented by Song (2011). Figure 5 shows the flowchart for the process.

The use of a genetic algorithm for this problem allows us to generate designs and evaluate performance based on full years of renewables input data while avoiding the tractability and convexity problems which affect gradient and branching-based solvers. However, the use of an evolutionary algorithm introduces a stochastic element to the solution procedure. Hence, more than one run may be required to give a measure of confidence in the solution.

\section{Case studies}

Two case studies are presented in this work. The cases consider locations with different levels of solar availability and variability, allowing the methodology to be stress-tested.

\subsection{Multi-objective design of stand-alone solar-based system for Chile}

For the first case study, we consider the design of an energy system for Collahuasi mine (Lat. 22.3 ${ }^{\circ}$ S, Long. $68.9^{\circ} \mathrm{W}$ ). Jointly owned by Anglo American PLC (44\%), Glencore Xstrata PLC (44\%) and Japan Collahuasi Resources B.V (12\%). It is third largest copper mine in the world and is located in the mine-rich Atacama region of Chile.

Historical solar radiation (GHI) data for the site over a period of 10 years (2003-2012) was obtained from the Department of Geophysics at the University of Chile (University of Chile, 2012). Electricity consumption data for the mine was obtained from the Chilean electricity dispatch authorities (CDEC-SING, 2016), with the hourly demand varying between 164 and 178MWh and a total daily demand of 4104.25MWh (Figure 6). The thermal demands of the plant were assumed to be $10 \%$ of the electrical demands due to lack of data. With direct heating accounting for $13 \%$ of the mining industry's energy end-use (Pellegrino et al. 2004), the assumption was considered reasonable.

Figure 7 shows the average of the total global radiation available per day $\left[\mathrm{kWh} / \mathrm{m}^{2} \cdot\right.$ day $]$. Solar radiation is highest highest between November and January and lowest in June/July.

300 synthetic solar input scenarios were generated for the optimization process based on the methodology decribed previously (Section 4). With the operation starting at midnight, the storage options were initialized to be $60 \%$ charged at the start of operation in order to meet the plant demands for the first morning. The NSGA-II parameters used in the study are shown in Table 1. Details about the other parameters and cost data used in the work and their sources may be found in Amusat et al. (2016). Hourly time steps were considered for the discretization of the entire model.

The optimization routine takes a long time to compute a solution, requiring up to $87 \mathrm{~h}$ with 12-core parallel computing on an Intel Xeon(R) processor (CPU E5-2440@ $2.40 \mathrm{GHz}$ ).

\subsubsection{Trade-off curve}

Figure 8 shows the non-dominated objective function values for 3 attempts. Each data point represents a different design. Moving from left to right indicates increasing reliability. A value of $\overline{L P S P}_{m}=0$ means that the design was able to meet the yearly demands in all the input years, while a value of $\overline{L P S P}_{m}=1$ means 


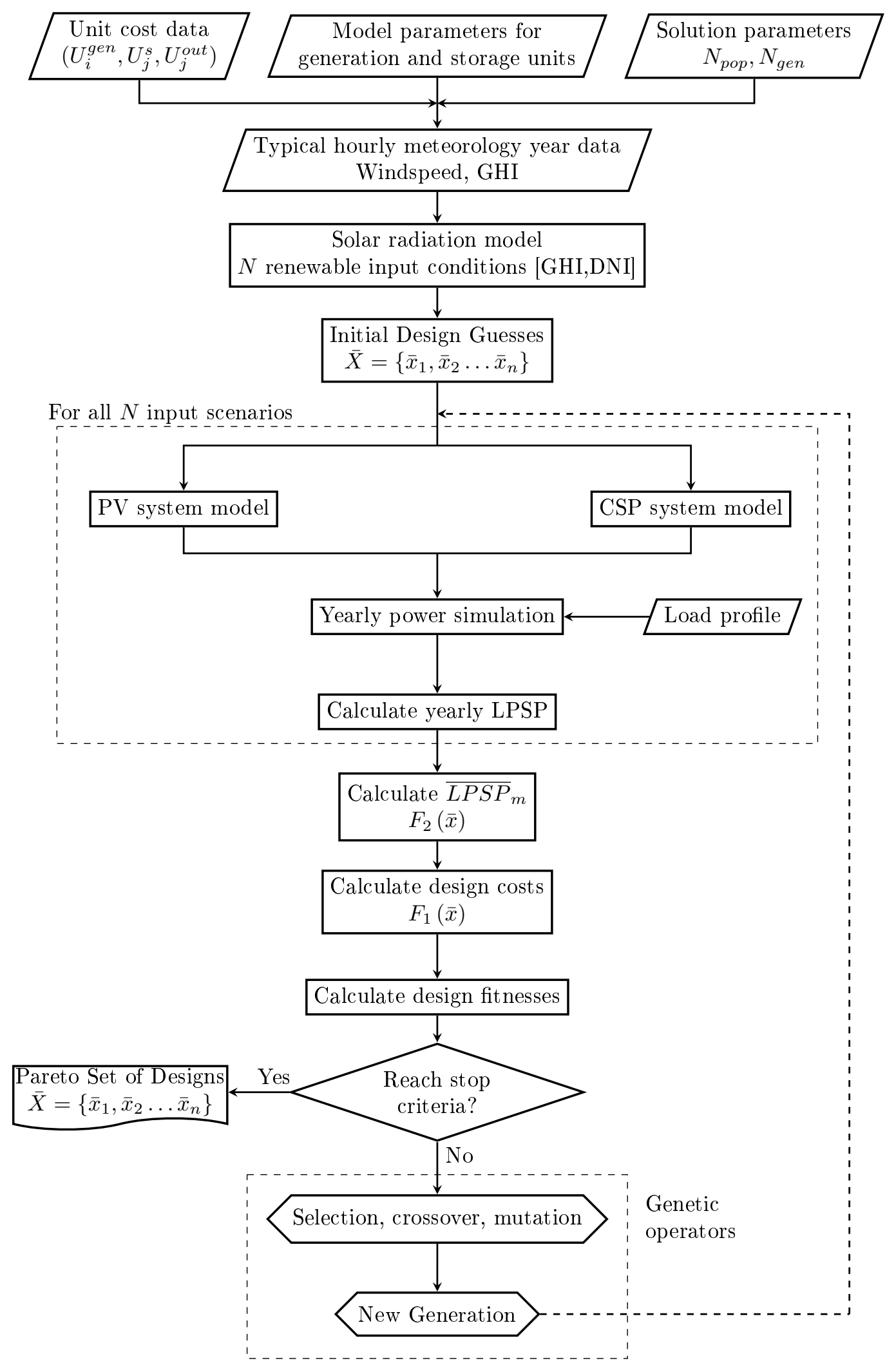

Figure 5: Flowchart for optimal sizing using multi-objective genetic algorithm. 


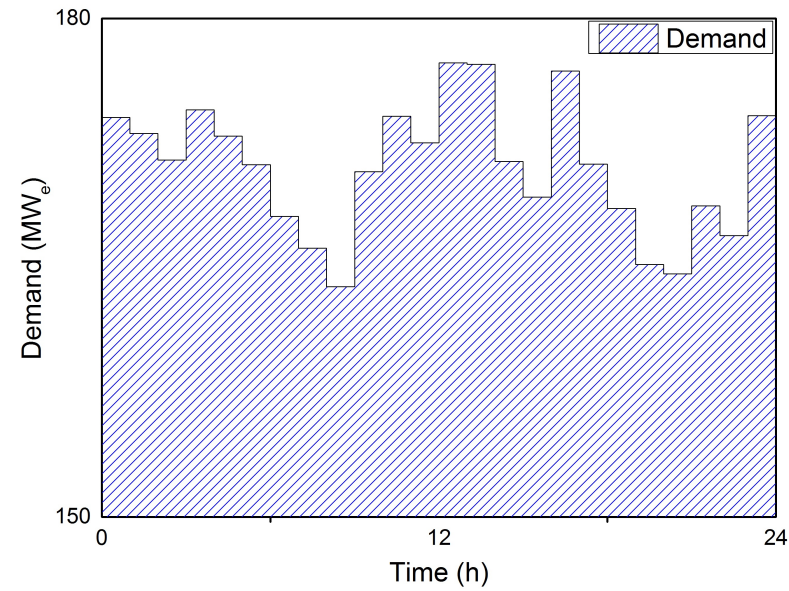

Figure 6: Daily electricity demand profile for the mine. The same demand profile was applied for all days of the year.

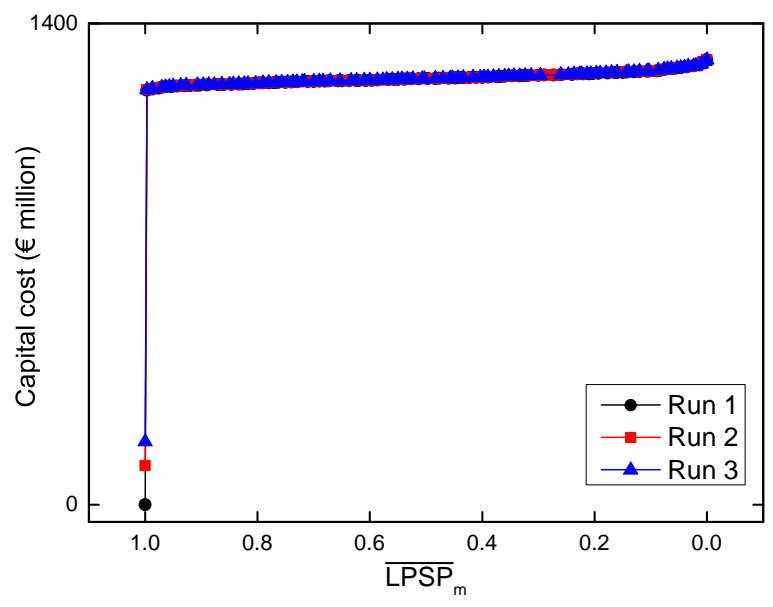

Figure 8: Full Pareto fronts with trivial $\left(\overline{L P S P}_{m}=1\right)$ solutions

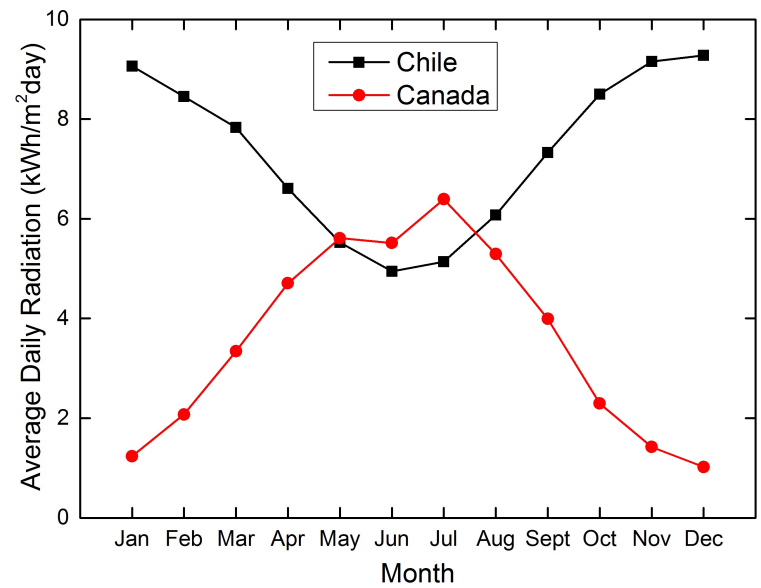

Figure 7: Average of total global radiation available per day $\left[\mathrm{kWh} / \mathrm{m}^{2}\right.$.day $]$ for each month for Chile and for Canada.

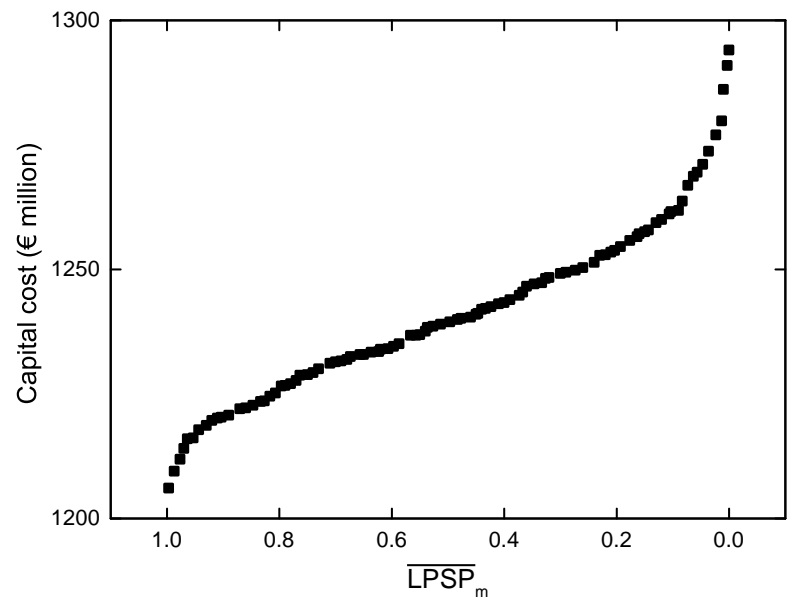

Figure 9: A magnified view of Run 1 after the removal of trivial solution

that the design was unable to fully satisfy the plant demands in any of the years. There is very little difference between the results of the three runs, giving a measure of confidence that set of non-dominated solutions have been identified well. The minimum cost solution involves doing nothing $\left(\overline{L P S P}_{m}=1, C C=0\right)$; the Pareto curve can be seen to converge towards this trivial solution on the left part of the Figure 8 . However, the solution provides no information and will be ignored. The minimum cost design is considered to be the next best solution; $\overline{L P S P}_{m} \in[0,1)$. For analysis of the designs, the Pareto front identified from the first run is considered.

Figure 9 shows the approximation to cost-reliability Pareto-optimal front. The capital cost varies by $7.3 \%$ ( $€ 88 \mathrm{M}$ ) over the entire reliability range. The small cost variation reflects the low variability in renewables input for the location (Amusat et al. 2016).

Of particular interest is the behaviour of the cost profile at high reliabilities. While the cost profile is nearlinear over most of the reliability range, the gradient of the curve increases rapidly over the final $20-30 \%$ of the range. The final $20 \%$ of the range accounts for $45 \%$ of the cost increase. This indicates that significant oversizing is required to meet all demand, all of the time. For the decision maker, this raises the question of whether it is essential to attain $100 \%$ reliability. In a case where the reliability requirement is flexible (the mine owner is willing to shut down the plant or run diesel generators for a short period in some years, for example), the designer has less expensive high-performance designs to choose from. For example, the design 
Table 2: Characteristics of least reliable design for Chile

\begin{tabular}{lcccc}
\hline PT capacity & MTS storage capacity & Rated MTS discharge capacity & LPSP & Capital cost \\
\hline $1208 \mathrm{MW}_{\text {th }}$ & $6358 \mathrm{MWh}$ & $178 \mathrm{MW}_{\mathrm{e}}$ & 0.9967 & $\in 1206.06 \mathrm{M}$ \\
\hline
\end{tabular}

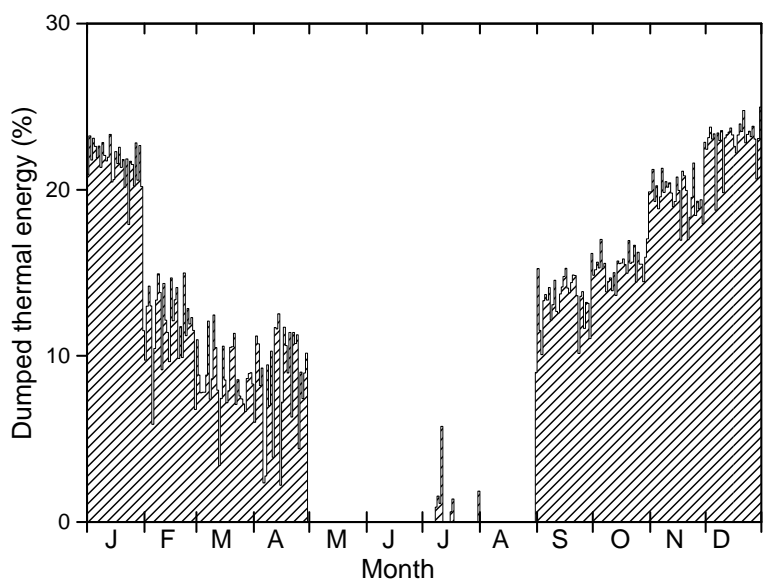

Figure 10: Daily excess thermal generation

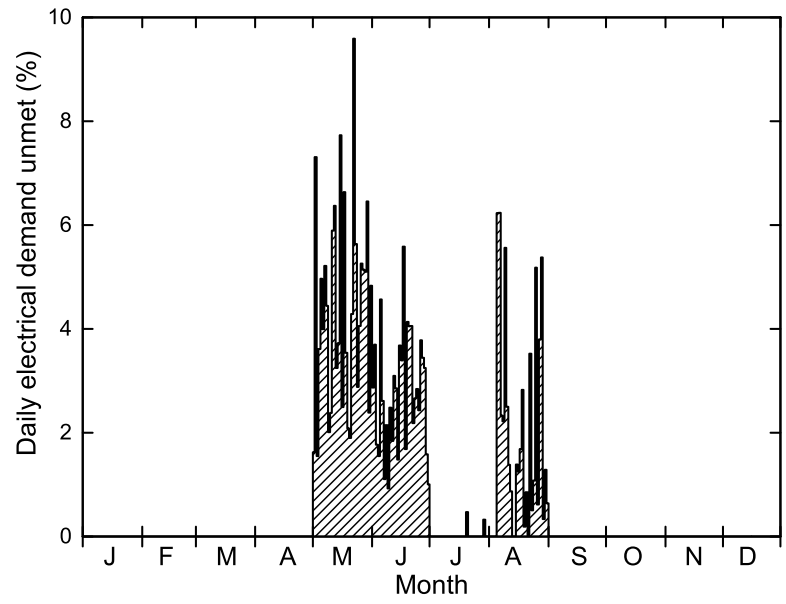

Figure 11: Percentage of daily demand unmet by design

with $80 \%$ reliability would typically only require diesel energy generation for a small number of hours in one out of five years and yet costs $€ 40 \mathrm{M}$ less.

\subsubsection{Energy system configuration}

For all the designs, the energy system configuration involves the installation of a power tower for generation and a molten salt two-tank system for thermal energy storage, with photovoltaics eliminated completely. Generation from the power tower meets demands during the day while heat and power are supplied through the MTS at night.

This is slightly different from the scheme obtained in the previous work (Amusat et al. 2016 ) in which PVs and PHES were used for peak shaving. Peak shaving is not possible here (see Section 5.1), so the PHES and PV technologies are not selected.

This change in configuration has an effect on the results, with slightly larger generation, storage and discharge capacities required to compensate for the energy previously supplied by the eliminated options.

\subsubsection{Performance of least reliable design under worst simulated conditions}

One of the reasons a new methodology was developed in this work was to provide the ability to make decisions based on information about the design performace in the entire year, not just one day or season. To demonstrate this, we consider the performance of the design with the lowest reliability (summarized in Table 2 under the worst of the input conditions generated. Figure 10 shows the fraction of the thermal generation dumped daily, while Figure 11 shows the fraction of the daily demand that that is left unsatisfied by the energy system. From the Figures, we see that:

1. Deficits in energy supply occur in late autumn and winter. For 8 months of the year, the energy system is sufficient to satisfy the demands of the mine. The relatively low dumping levels suggest that energy generation across the year does not change significantly between seasons.

2. The energy system fails for $161 \mathrm{~h}$, translating to $1.9 \%$ of the year. Thus, the design is able to meet demands for over $98 \%$ of the year. Analysis of the total external energy requirements showed that only $0.77 \%$ of the annual demand will need to be satisfied externally.

The least reliable design generated has the smallest generation and storage capacities of all the designs generated, as can be seen in Figure 12. This means that all the other designs will always perform at 


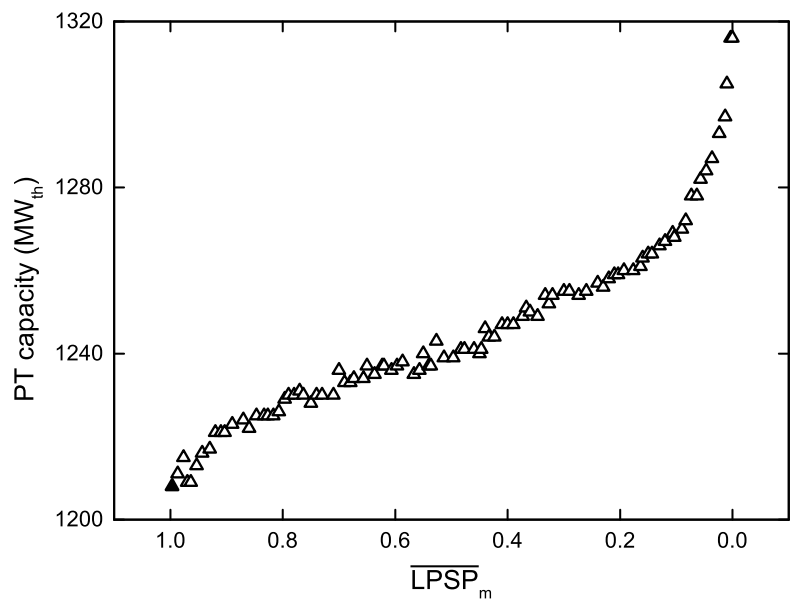

(a) Power Tower

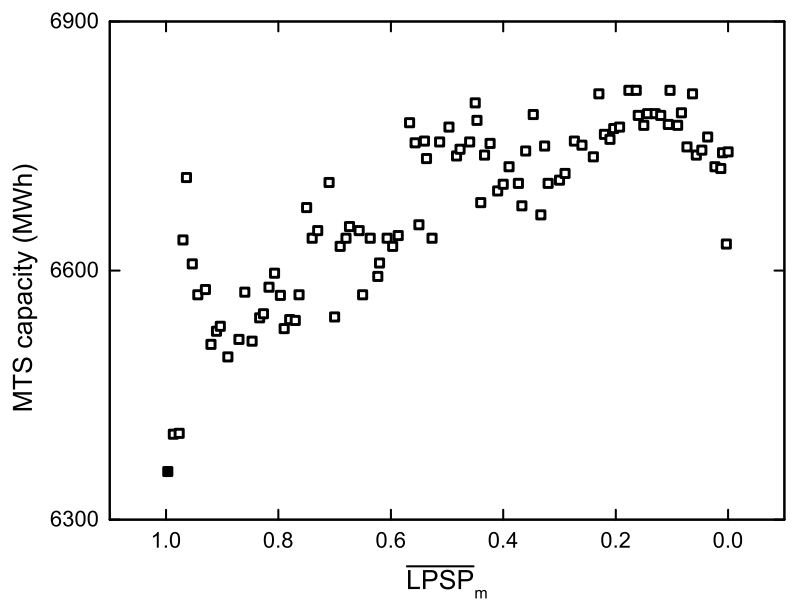

(b) Molten salt thermal storage

Figure 12: Variation of installed generation and storage capacities over reliability range. The shaded symbols represent the capacities for the least reliable design.

least equally as well as the least reliable design irrespective of scenario, as they will always be able to generate and/or store more energy. Thus, the performance of the least reliable design in any scenario provides a limit on how poorly the other designs will perform under that input scenario. Combining this with the information obtained from the worst case scenario, we can conclude that all the designs generated will be able to meet demands for over $98 \%$ of the year.

3. On any given day, the design is able to meet more than $90 \%$ of the daily demands of the plant. The design will always satisfy demand for at least 21 hours a day.

The same sort of analysis can be carried out for any of the designs generated. The methodology therefore provides the designer with necessary information about the designs which are critical to the decision-making process. These sorts of information were not available with the previous approach.

The results from this case study suggest that for locations with low renewables variability, little spread in the capital costs of the designs over the entire reliability range should be expected. All the designs perform well even under poor input conditions. The decision of the design point is therefore less likely to be based on the cost of the designs for such locations.

It is expected that a location with higher variability in renewables input will reveal a larger spread in capital costs over the entire reliability range. This is investigated in the second case study.

\subsection{Canadian case study}

The second case study considers relocating the fictional Chilean mine to Alberta, Canada (Lat. $51.0^{\circ} \mathrm{N}$, Long. $114.0^{\circ} \mathrm{W}$ ). The choice of Canada as an alternative site for the mine was influenced by its significant mining activities, large variability in renewables availability and the availability of historical solar radiation data. Testing the methodology at a location with renewables input conditions quantitatively and qualitatively different from Chile allows us to demonstrate the methodology more generally.

Historical solar radiation (GHI) data for the site for 8 years (2005-2012) was obtained from the United States national solar radiation database (NREL, (2015)). Again, 300 synthetic solar input scenarios were considered. The average of the total global radiation available per day for each month for the location is shown in Figure 7. The figure shows that solar resource availability is significantly lower than in Chile. It also shows that the period of lowest resource availability for one location corresponds to the period of highest availability for the other.

The parameters and cost data used remain the same as for the first study. 


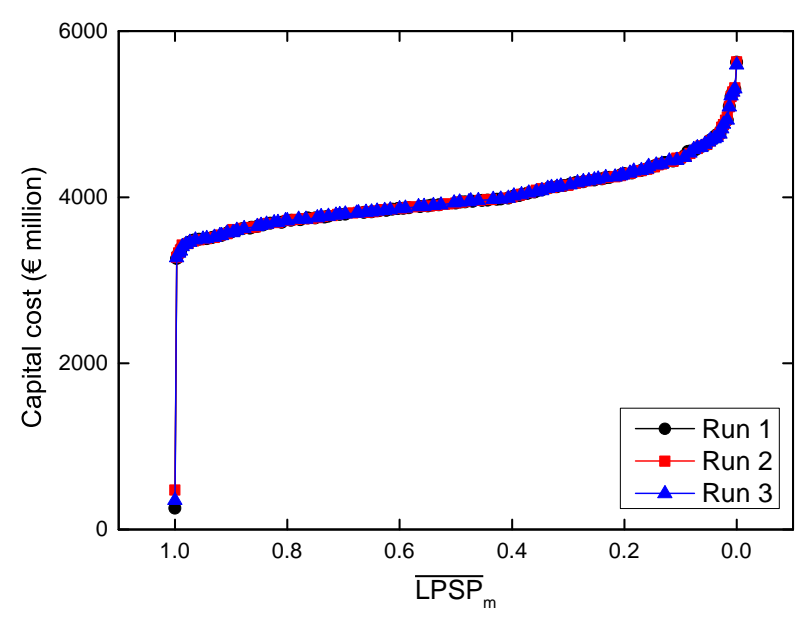

Figure 13: Full Pareto fronts with trivial $\left(\overline{L P S P}_{m}=1\right)$ solutions

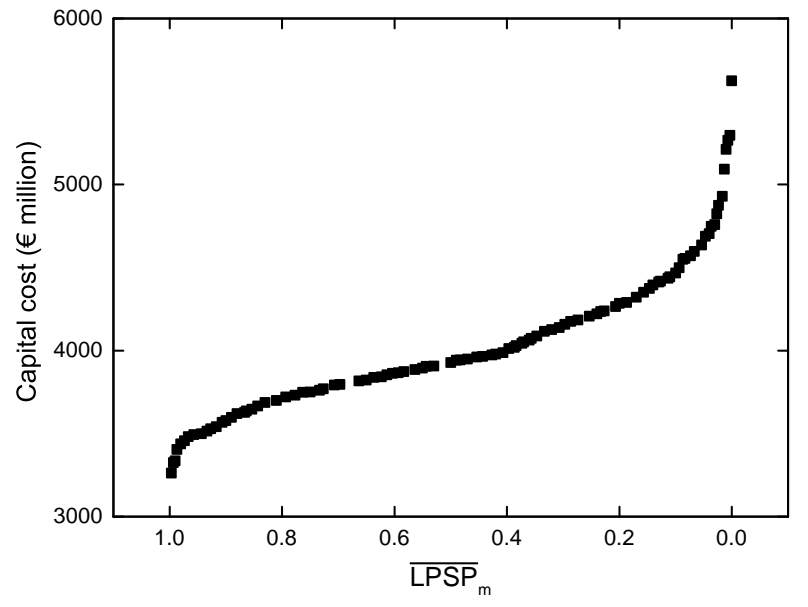

Figure 14: A zoomed in view of Run 1 after the removal of trivial solution

\subsubsection{Trade-off curve}

Figure 13 shows the non-dominated objective function values for 3 attempts. Again, there is very little difference between the results of the three runs, giving a measure of confidence that set of non-dominated solutions have been identified well. Again, the trivial solutions are ignored. For analysis of the designs, the Pareto front identified from the first run is considered.

Figure 14 shows the approximation to cost-reliability Pareto-optimal front. The capital cost varies by $72.5 \%$ ( $€ 2.36 \mathrm{bn}$ ) over the entire reliability range. The comparatively high cost variation observed compared to the Chile case reflects the significantly higher variability in renewables input in Canada.

Again, the behaviour of the curve at the high end of the reliability range is of interest to the designer. Increasing the system reliability by $1 \%$ from $\overline{L P S P}_{m}=0.01$ (one failure every 100 years) to $\overline{L P S P}_{m}=0$ accounts for $17 \%$ of the total cost increase. These results suggest that significant oversizing is required to obtain a fully reliable design and highlights the problem with worst case designs for regions with large renewables variability. Given that the average lifetime of a remote mine is typically about 15 to 20 years (Paraszczak and Fytas, 2012, Carvalho et al., 2014), such high system reliabilities may not be critical.

\subsubsection{Energy system configuration}

The energy system configuration is the same as the one for Chile for all the designs, with only the thermal generation and storage options selected. This is the same configuration obtained for the designs generated in the previous work.

\subsubsection{Performance of least reliable design under worst simulated conditions}

The daily performance of the least reliable design (presented in Table 3) under the worst generated solar input conditions is shown in Figure 16. The following conclusions can be drawn:

1. The design is able to meet the demands of the plant for 8 months of the year (February through September). During this period, significant energy dumping occurs, with less than half of the energy generated in summer actually collected for use in the system (Figure 15). This suggests that the level of thermal energy generation varies significantly between seasons.

2. The design fails for $6.9 \%(608 \mathrm{~h}$ ) of the year, meaning the design (and all others generated) will meet the load demands for over $93 \%$ of the year. Analysis of the total external energy requirements revealed that $6.02 \%$ of the annual demand will need to be satisfied externally.

3. The design performs poorly in months with low renewables availability, with up to $54 \%$ of the load demand (spread over 14 hours) needing to be satisfied from outside the integrated energy system. 
Table 3: Characteristics of least reliable design for Canada

\begin{tabular}{lcccc}
\hline PT capacity & MTS storage capacity & Rated MTS discharge capacity & LPSP & Capital cost \\
\hline $3855 \mathrm{MW}_{\text {th }}$ & $11744 \mathrm{MWh}$ & $180 \mathrm{MW}_{\mathrm{e}}$ & 0.9967 & $\in 3262.12 \mathrm{M}$ \\
\hline
\end{tabular}

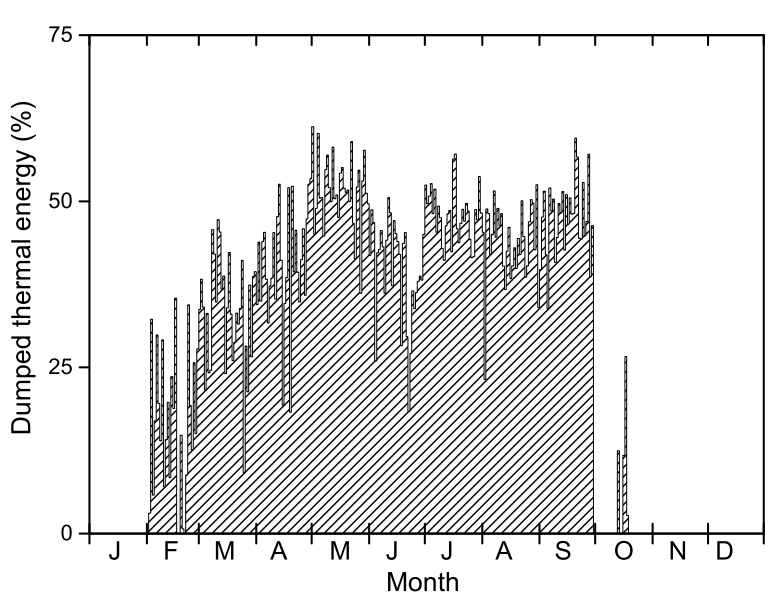

Figure 15: Daily excess thermal generation

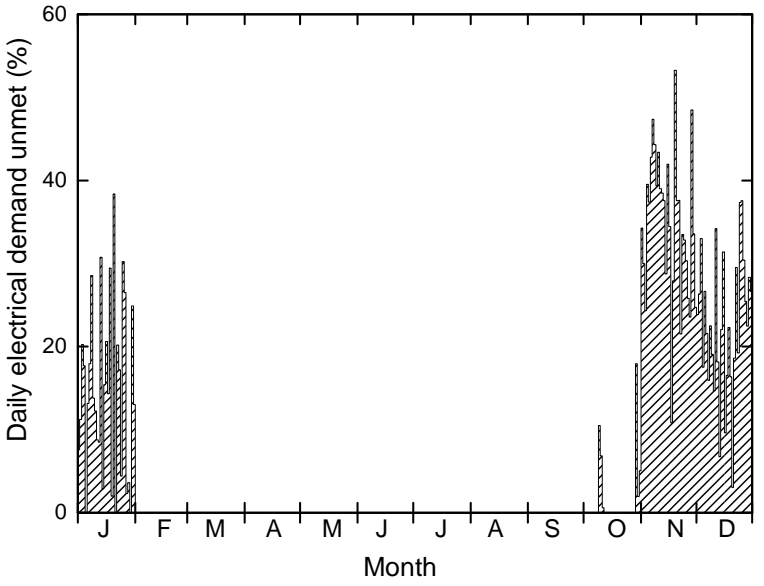

Figure 16: Percentage of daily demand unmet by design

Compared to the Chilean case study, the degree of energy dumping required, the frequency of power failure and the extent of power failure are seen to be significantly higher. This highlights the significant role that variability can play on energy system performance.

For locations such as Northern Chile where clusters of mining operations exist, the excess generation available for most of the year opens up the possibility of energy trading with neighbouring mines in months with high solar availability. This could generate extra income to partly or fully cover the cost of external energy supply in the winter months. However, such a scenario would require that the output capacity of the power block be increased, thereby incurring additional costs.

From Table 3, it can be seen that the MTS discharge capacity is higher than that required in the Chilean case. This is because the Canadian MTS storage system is larger and thus requires more electric heating.

\section{Conclusion}

The techno-economic analysis of a renewables-based energy system integrating thermal and electrical generation with large-scale storage has been investigated. The methodology presented shows how inter-year variability can be taken into consideration in the sizing of such systems at the design stage, with an interyear reliability measure developed in the work. The results show that the degree of variability is reflected in the range of the costs of the Pareto-optimal designs. An analysis of the designs reveals that significant cost savings are possible for little loss in reliability and performance. The decision-maker's definition of reliability therefore has a significant impact on the capital cost of the system, with oversizing often required to guarantee energy security.

The methodology presented is applicable to any location, can easily be extended to incorporate other generation and storage alternatives, and provides the decision maker with necessary information about a number of alternative designs based on which sizing decisions can be made.

\section{Acknowledgments}

The authors would like to acknowledge the funding provided by the Nigerian government through the presidential scholarship for innovation and development (PRESSID) scheme for this research. P.R. Shearing acknowledges funding from the Royal Academy of Engineering. 
$521 \quad \bar{X}$

${ }^{522} \quad \bar{x}_{n}$

$523 \overline{L P S P}_{m}$

$524 \overline{O P}$

${ }_{525} \dot{E}_{i, \tau}^{\text {gen }}$

${ }^{526} \quad \dot{E}_{j, \tau}^{\text {out }}$

Q heating

${ }_{527} Q_{j, \tau}$

${ }_{\mathbf{5 2 8}} \quad \dot{S}_{\tau}^{e l} \quad$ Unmet electrical load [MW]

${ }_{529} \quad \dot{S}_{\tau}^{\text {th }} \quad$ Unmet thermal load [MW]

530 $A_{i}^{\text {gen }} \quad$ Area of generation unit $i\left[\mathrm{~m}^{2}\right]$

${ }_{531} C_{i}^{g e n} \quad$ Installed capacity of generation unit $i[\mathrm{MW}]$

${ }_{532} C_{j}^{\text {out }} \quad$ Nominal output capacity of unit $j[\mathrm{MW}]$

${ }_{533} \quad C_{j}^{s} \quad$ Installed storage capacity of unit $j$ [MWh]

${ }_{534} C C(\bar{x}) \quad$ Capital cost of design $\bar{x}[€]$

${ }_{535} E_{\tau}^{e x t} \quad$ External energy requirement in time interval $\tau$ [MWh]

536 $\quad E_{j}^{s} \quad$ Energy stored in option $j$ [MWh]

${ }_{537} i \quad$ Generation option

${ }_{538} \quad j \quad$ Storage option

539 $\quad L P S P$ Loss of power probability within the year, unitless

${ }_{540} n_{g} \quad$ Number of generation options

${ }_{541} n_{s} \quad$ Number of storage options

${ }_{542} N_{\text {design }}$ Number of designs

${ }_{543} \quad$ PFT $\quad$ Power failure time $[\mathrm{h}]$

${ }_{544} R(\bar{x}) \quad$ Reliability of design $\bar{x}$, unitless

545 $\quad T \quad$ Total number of hours [h]

$546 \quad U_{j}^{s}$

${ }^{547} U_{i}^{g e n}$

${ }_{548} U_{i}^{\text {out }}$

$549 U_{i}^{g e n}$

${ }^{550} \quad U_{j}^{\text {out }}$

$551 \quad U_{j}^{s}$
Energy-specific cost of storage option $j[€ / \mathrm{kWh}]$

Unit cost of generation option $i\left[€ / \mathrm{m}^{2}\right]$

Capacity-specific cost of storage option $j\left[€ / \mathrm{kW}_{\mathrm{e}}\right]$

Unit cost of generation option $i\left[€ / \mathrm{m}^{2}\right]$

Capacity-specific cost of storage option $j\left[€ / \mathrm{kW}_{\mathrm{e}}\right]$

Energy-specific cost of storage option $j[€ / \mathrm{kWh}]$ 


\section{References}

Abbes, D., Martinez, A., Champenois, G., Apr 2014. Life cycle cost, embodied energy and loss of power supply probability for the optimal design of hybrid power systems. Mathematics and Computers in Simulation $98,46-62$.

URL http://dx.doi.org/10.1016/j.matcom.2013.05.004

Al-Shamma'a, A., Addoweesh, K., 2014. Techno-economic optimization of hybrid power system using genetic algorithm 38 (12), 1608-1623.

Amusat, O. O., Shearing, P. R., Fraga, E. S., 2015. System design of renewable energy generation and storage alternatives for large scale continuous processes. In: Gernaey, K. V., Huusom, J. K., Gani, R. (Eds.), Computer Aided Chemical Engineering. Vol. 37. Elsevier, pp. 2279-2284.

Amusat, O. O., Shearing, P. R., Fraga, E. S., 2016. Optimal integrated energy systems design incorporating variable renewable energy sources. Computers \& Chemical Engineering, - . URL http: //www.sciencedirect.com/science/article/pii/S009813541630268X

Bermudez, J., Ruisanchez, E., Arenillas, A., Moreno, A., Menendez, J., Feb 2014. New concept for energy storage: Microwave-induced carbon gasification with CO2. Energy Conversion and Management 78, 559564.

URL http://dx.doi.org/10.1016/j.enconman.2013.11.021

Carvalho, M., Romero, A., Shields, G., Millar, D., 2014. Optimal synthesis of energy supply systems for remote open pit mines. Applied Thermal Engineering 64, 315 - 330. URL http: //www.sciencedirect.com/science/article/pii/S135943111300937X

Centro de Despacho Economico de Carga del Sistema Interconectado del Norte Grande de Chile, ???? Retiros de energía a clientes. [Online]. Available at: http://cdec2.cdec-sing.cl/, accessed 04 May 2014.

Chauhan, A., Saini, R., Oct 2014. A review on integrated renewable energy system based power generation for stand-alone applications: Configurations, storage options, sizing methodologies and control. Renewable and Sustainable Energy Reviews 38, 99-120.

URL http://dx.doi.org/10.1016/j.rser.2014.05.079

Deb, K., Pratap, A., Agarwal, S., Meyarivan, T., Apr 2002. A fast and elitist multiobjective genetic algorithm: Nsga-ii. IEEE Trans. Evol. Computat. 6 (2), 182-197.

URL http://dx.doi.org/10.1109/4235.996017

Departamento de Geofísica de la Universidad de Chile, 2012. Evaluación del recurso solar. [Online]. Available in Spanish at: http://walker.dgf.uchile.cl/Explorador/Solar2/, accessed 31 March 2014.

Diaf, S., Belhamel, M., Haddadi, M., Louche, A., Feb. 2008. Technical and economic assessment of hybrid photovoltaic/wind system with battery storage in corsica island. Energy Policy 36 (2), 743-754.

URL http://www.sciencedirect.com/science/article/pii/S0301421507004788

Duffie, J., Beckman, W., 2013. Solar Engineering of Thermal Processes: Fourth Edition. John Wiley \& Sons, Inc., Solar Energy Laboratory, University of Wisconsin-Madison, United States.

URL http://www.scopus.com/inward/record.url?eid=2-s2.0-84891584184\&partnerID=40\&md5= a4627e279ca41900c9b4602d84146d08

Dufo-Lopez, R., Bernal-Agustin, J. L., Dec. 2008. Multi-objective design of pv-wind-diesel-hydrogen-battery systems. Renewable Energy 33 (12), 2559-2572.

URL http://www.sciencedirect.com/science/article/pii/S0960148108000724

Kaabeche, A., Ibtiouen, R., May 2014. Techno-economic optimization of hybrid photovoltaic/wind/diesel/battery generation in a stand-alone power system. Solar Energy 103, $171-182$. URL http://www.sciencedirect.com/science/article/pii/S0038092X14000954 
Khatod, D. K., Pant, V., Sharma, J., Jun 2010. Analytical approach for well-being assessment of small autonomous power systems with solar and wind energy sources. IEEE Transactions on Energy Conversion $25(2), 535-545$.

URL http://dx.doi.org/10.1109/TEC.2009.2033881

Lahcene, B., May 2013. On pearson families of distributions and its applications. African Journal of Mathematics and Computer Science Research 6(5), 108-117.

MATLAB, 2014. version 8.3 (R2014a). The MathWorks Inc., Natick, Massachusetts.

National Renewable Energy Laboratory (NREL), 2015. National Solar Radiation Data Base. [Online]. Available at: http://rredc.nrel.gov/solar/old_data/nsrdb/, Accessed 30 April 2014.

Osborn, J., Kawann, C., 2001. Reliability of the US Electricity System: Recent Trends and Current Issues. Energy Analysis Department, Ernest Orlando Lawrence Berkeley National Laboratory, LBNL-47043, Berkeley, CA.

Ould Bilal, B., Sambou, V., Ndiaye, P., Kebe, C., Ndongo, M., Oct 2010. Optimal design of a hybrid solarwind-battery system using the minimization of the annualized cost system and the minimization of the loss of power supply probability (lpsp). Renewable Energy 35 (10), 2388-2390.

URL http://dx.doi.org/10.1016/j.renene.2010.03.004

Paraszczak, J., Fytas, K., 23-30 Mar 2012. Renewable energy sources - a promising opportunity for remote mine sites? In: International Conference on Renewable Energies and Power Quality (ICREPQ 12). Santiago de Compostela (Spain).

Pearson, K., 1916. Mathematical contributions to the theory of evolution. xix. second supplement to a memoir on skew variation. Philosophical Transactions of the Royal Society of London A: Mathematical, Physical and Engineering Sciences 216 (538-548), 429-457.

Pellegrino, J., Margolis, N., Justiniano, M., Miller, M., Thedki, A., 2004. Energy use, loss and opportunities analysis: Us manufacturing and mining. US Department of Energy.

Song, L., 2011. NGPM - A NSGA-II program in Matlab v1.4. Aerospace structural dynamics research laboratory, College of Astronautics, Northwestern Polytechnical University, China. URL http://uk .mathworks.com/matlabcentral/fileexchange/31166-ngpm-a-nsga-ii-program-in-matlab-v1-4

Tina, G., Gagliano, S., 2008. Probability analysis of weather data for energy assessment of hybrid solar/wind power system. In: proceedings of 4th IASME/WSEAS international conf. Energy, Environment, Ecosystems and sustainable development. pp. 217-223.

Tina, G., Gagliano, S., Raiti, S., May 2006. Hybrid solar/wind power system probabilistic modelling for long-term performance assessment. Solar Energy 80 (5), 578-588.

URL http://dx.doi.org/10.1016/j.solener.2005.03.013

Yang, H., Lu, L., Burnett, J., Sep 2003. Weather data and probability analysis of hybrid photovoltaic-wind power generation systems in hong kong. Renewable Energy 28 (11), 1813-1824. URL http://dx.doi.org/10.1016/S0960-1481(03)00015-6

Yang, H., Wei, Z., Chengzhi, L., Feb 2009. Optimal design and techno-economic analysis of a hybrid solarwind power generation system. Applied Energy 86 (2), 163-169.

URL http://dx.doi.org/10.1016/j.apenergy .2008.03.008

Yang, H., Zhou, W., Lu, L., Fang, Z., Apr. 2008. Optimal sizing method for stand-alone hybrid solar-wind system with lpsp technology by using genetic algorithm. Solar Energy 82 (4), 354-367.

URL http://www.sciencedirect.com/science/article/pii/S0038092X07001831 